\title{
Protest between Discourse and Practice - On the Relationship of Affective Discourses and Practices of Moving Protest Forms with the Example of the Yippie Festival of Life
}

\author{
Franka Schäfer \\ Institute of Sociology, Faculty of Humanities and Social Sciences, Open University, Germany
}

Copyright $(2017$ by authors, all rights reserved. Authors agree that this article remains permanently open access under the terms of the Creative Commons Attribution License 4.0 International License

\begin{abstract}
In the following, the paper addresses the unfinished discussion of the affective in sociological theory. Major objective is to argue for an active and positive connotation of the decentering of the subject within the framework of the version of the affective that sociology implemented under great effort - one might think of the achievements of post structuralism - not so long ago. For this reason, a research program using a discourse-analytically informed sociology of practice - relating to the affective - is recommended. It borrows ontologically from Massumi [1], whose concept of the affective applies empirically in the tradition of Grossberg [2] and Clough [3] and tests it against sociology of protest by borrowing from Stähli's [4] concept of the collective. The event of the Chicago Festival of Life 1968 gives an example how to do a practice-theoretical sequential filmanalysis with the methodological focus on artefacts, bodies, moves, space, time and discourse. It brings us to the findings that with such a research design one needn't with the subject in focus throw the affect as such overboard as well, but could rather - and Patricia T. Clough [3] is right with that - implement the affective turn in such a way that it refers to the discontinuity of the subject and conceives physicalness and materiality in general as constituting moments of sociality [3]. The essence of the reflections is, finally, the suggestion that affectedness is practice which, in its eventuality as a historically contingent intensity zone, like G. Deleuze and F. Guatari [31] highlighted, is constituted with potential for transformation and can only be empirically grasped.
\end{abstract}

Keywords Sociology, Practice Theory, Discourse Theory, Sociology of Protest, Sociology of Affect

\section{Introduction}

Sociologists struggle not only in the context of sociological reversion semantics such as those of religion or terror. They struggle as well with any theoretical combination with the status value of the affectivity, and its role in the production of sociality. Even in the classical sociological research fields of work sociology, gender research, organisational sociology, and protest research, the public discussion of the concept of affect, in the face of affective communication, affective experiences, affect control, or affective orientation, does not abate. Especially in the face of an affect-orientated media landscape, in times of visually-affecting crisis reporting on recurring forms of terror, reality TV formats and personalised video messages of public figures - which can't but be perceived both affirmative and agonal messages as affectively authored and observed - a sociologically-distanced and theoretical analysis of the affective is required. Additional to resulting in studies like Bütow, Kahl and Stach's [5] on the connection between youthfulness, affectivity and education, Gutierrez Rodriguez' [6] on affectivity in nursing careers, Endert's [7], Butler's and Mohrmann's [8] on the role of the affective in forms of extremism, Diehl's [9] on the role of affectivity in politics, or Seyfert's [10] on the relationship between institutions and affects, the very relevance of the sociological analysis of the affective should be taken as occasions for further discussions about looking at ways of producing extraordinariness. Extraordinariness comes in the process as both - short-term affecting episodes with a surprise effect, as well as sustained affecting of emotional involvement of organised extraordinariness [12]. Dealing with the social dimension of being affected in the context of current sociological theories has so far been clearly under-represented, in contrast to the importance that the classic proponents of the subject such as Durkheim, Weber, Parsons, or Simmel attach to the affective 
$[11,10]$. Even highly-valued theoretical orientations of current sociology, e.g. theories of practice, give the affective a wide, unproductive berth, for reasons discussed in more detail below.

Only at the end of the 1990s did Anglo-American sociology, and with a slight delay also German sociology in the last few years, once again become sensitive to the affective. That is now being debated under the label affective turn (e.g. by M. Gregg and G. J. Seigworth [13]). As much as this appreciation of the affective may be welcomed, the debate, which with regard to this turn often revolves around the extraordinary, the physical, the magic, and often the religious, careers into a strange oblique position sometimes. It runs the risk, through the link to the emotion and incomprehensibility of the affective, of taking an unnecessary move backwards on the subject and its experiences of the affective. The purpose of my next contribution is to show that this move does not have to be backwards, as we are just starting to notice the merits of sociologies that are not centred on the subject, but rather make the works of actor nets like B. Latour [14], the living like R. Braidotti [15], the material like I. van derTuin and Dolphijn [16] or the practice like F. Hillebrandt $[17,18]$ the object of sociological research.

In the following, the paper adresses the unfinished discussion of the affective in sociological theory, and argues for an active and positive connotation of the decentering of the subject within the framework of the version of the affective that sociology implemented under great effort - one might think of the achievements of poststructuralism - not so long ago. For this reason, a research programme using a discourse-analytically informed sociology of practice relating to the affective - is recommended. It borrows ontologically from Massumi [1], whose concept of the affective applies empirically in the tradition of Grossberg [2] and Clough [3] and tests it against sociology of protest by borrowing from Stähli's concept of the collective [4]. In this way, instead of moving backwards, a small but essential step can be made in the opposite direction.

\section{Protest between Discourse and Practice}

The basic starting point of the authors sociological work is always the relationship between discourse and practice theory which, in the authors opinion, remains too paralellistic. Onto that relationship she wants to force synergy effects through the strengthening of the Foucaultian concept of events, in the context of discourse-analytically-informed practice sociology of protest. As the contributions to the current discussion about the concept of affect emphasise [8], practical forms of protest are particularly suitable for dealing with the affected and the affectative from the theoretical perspective of discourse and practice. Current sociologies of protest support the thesis that affectation is constitutive of this form of practice and that no protest takes place without affecting like H. Dietz highlights [19].

\subsection{Empirical Occasion}

In order to meet the methodological requirements of every sociology of practice, to take a synthetic relationship between theory and empiricism seriously, the paper returns to the empirical datum of Chicago Festival of Life [20,21], which took place in 1968 in the United States of America, to illustrate the remarks: The practices of the protest at the time, which took place under the codename Yippie! during the Festival of Life, are considered to be, in the sense of a sociology of practice, a protester event without precedent for successive protests of sequential nature. Under the motto We are young, we are international and our revolution is a party, still unprecedented practice forms of protest culminated in the event of the Yippie Festival of Life in Chicago 1968 and apparently integrated, in addition to ironic elements, strengthened practices of being affected into a performative practice of disorder, or outrageousness, which the author describes often in reference to a song title of Hamburg hip-hop and electropunk band Deichkind - with the term RemmiDemmi. ${ }^{1}$

The Chicago Festival of Life, as a serial event, like Foucault [22] highlights it, led together with others to the emergence of new forms of protest practice, pulling in uninvolved and differently socialised bodies in the practice form of protest. Especially practice forms that resulted in affectedness of socialised bodies - and this becomes important once again when it comes to the conceptual definition of affectedness as a result of implementation evolved into protest forms that became the foil for subsequent protest movements. Yippie! protest is subsequently interpreted by me, in terms of Foucault, as an event which becomes a breakpoint between two fixed conditions [32] and one starting point of a genealogy of the present of protest.

Why, though, the effort of a genealogy of the present of protest instead of a conventional research of protest? On the one hand, because we've known since Foucault that one can describe realities only in their disappearance. At the moment we are far enough removed to be able to contemplate the protests of the cultural revolution, because as one notices from all the efforts to keep them going, they are increasingly disappearing in this digital age. ${ }^{2}$

1 Single Remmidemmi (Yippie Yippie Yeah) (2006) from the 3rd album „Aufstand [Rebellion] im Schlaraffenland“, produced by Island Records. 2 Through globally oriented intensified media attention, it seems as if a revitalisation of performative protests were on the agenda, yet despite the "participatory revolution" declared by the FSO, "unconventional political participation" mainly involves signature collections and classical demonstrations [23]. 


\subsection{Methodology}

Practice theory in general lays interest on how to contain the physical implementation of practice and its own special quality. Besides the human body and mind, the discourse oriented perspective of practice theory used here, takes into account the crucial part of objects, knowledge, symbols, discourses, structure, and processes in everyday life [24]. Single practices of different forms of actions (formations of practice) are conceptualized as happenings of sayings and physical doings and the association between socialized bodies and material elements enabling the affordances of things [25-26]. Whereas in classical theories of action the human agent stands at the center, so called formations of practice are similar to conventions of different elements of discourses, socialized bodies, and materiality - similar to Bruno Latours [27] actants in Actor - Network -Theory, which effect practice within their special associations and combinations. The social in that prospective is in fact "the name of a type of momentary association which is characterized by the way it gathers together into new shapes" [14, p.65]. Especially the matter of physic artifact and the agency of materiality change the prospective of the social compared to conventional theories of action: "If action is limited a priori to what 'intentional', 'meaningful' humans do, it is hard to see how a hammer, a basket, a door closer, a cat, a rug, a mug, a list, or a tag could act. (...) By contrast, if we start from the controversies about actors and agencies, then 'anything' that does modify a state of affairs by making a difference is an actor - or, if it has no figuration yet, an actant" [14, p. 71]. The innovative theoretical concepts imply a considerable shift in the traditional sociological perspective on body, mind, things, knowledge, discourse, structure, process, and agency [24] and force you to painstaking ask, “(...) who and what participates in the action (...), even though it might mean letting elements in, which, for lack of a better term, we would call non humans. (...) For sociologists of associations, what is new is (...) that objects are suddenly highlighted not only as being full-blown actors, but also as what explains the contrasted landscape we started with, the overarching powers of society, the huge asymmetries, the crushing exercise of power", like Latour did [14, p. 72].

Moreover, methodologically, as mentioned within the framework of the theories of practice by Reckwitz [24], and currently a focus of F. Hillebrandt's [26], practices that are investigated are always follow-up practices. That is why an ethnography, a live sociology, etc. always remain mere extracts of a form of practice. If, however, we are trying to do not only dense descriptions and microsociology, which is of course legitimate for certain fields of research, but not always possible, we must necessarily follow the actants in both directions, in the sense of Latour [14]. One analyses what it is that must come together so that past and current practice are put into effect equally before one can take a closer look at what role being affected plays in practice forms of protest. Foucault's notion of the discourse event gives us the necessary orientation for where to begin when we work out genealogically from which point events go in series, and why elsewhere the author endeavours to bring the discourse-orientated and practice concept-orientated theoretical approaches synergetically in dialogue with each other.

Both theoretical positions acknowledge and establish that the separation between discourse and practice can not be sustained completely, but up to now one has to decide for a discourse theory with a weak concept of practice that either does not know the actor, or has a very strong concept of the actor. Or one decides, in the continuation of Bourdieu, for a theory of practice in which the discourse, however, is always tied to the position of the speaking actor in the social space itself, and in the respective field, and remains merely a representation of extra-discoursive conditions. The price to be paid in the case of the latter position is a hitherto extremely weak concept of discourse that cannot be differentiated from the modern theories of practice that are currently growing in importance. The position taken by the author here, therefore, comprises of consistently interpret actors as part of practices in the form of socialised bodies, as well as artefacts - including texts and linguistic material or symbolic material - as elements from which formation practices come about that link up into practice forms.

\subsection{Yippie! Protest}

What does it mean, then, to examine this theoretical foil of affectation and practice forms of protest? The socialised bodies that are today bundled together as Yippies! fed on the new Left and the Anti-Vietnam Mobilization Movement (MOBE) in the run-up to the Chicago Festival of Life. In the course of extravagant festivities, the Youth International Party was founded. The initial letters of the party name were abbreviated to Yip and the Yippies! had come into the world. In New York, the first protests were yip-ins and yip-outs, as simple beings for increasing awareness, live music and a performance theatre. This later evolved into Outrageousness as the main protest form and later as the Chicago Festival of Life as the counterpart of the nomination event of the Democrats for the presidential election. The democratic convention was called the Festival of Death because of the continuation of the Vietnam War, which was a major theme. In regards to affectedness it is interesting to know that the Yippie! protests became effective mainly through discursive mechanisms that had been created by the Festival of Life previously, and had an affective effect on the socialised bodies of bystanders. Statements spread through different media channels, for example, that Yippies would burn money, mix LSD into the drinking water and block streets in order to disturb the Democrat assembly. Here the materiality of the discourse is shown clearly, as then the city of Chicago prepared for the worst, even if none of the prophecies were fulfilled and the Yippie! protests themselves remained nonviolent. 
Another form of practice that took place within the framework of the Yippie protests - and this is the second assumption with regard to affecting - is that mainly the street as theatre, the public space as a backdrop, and bystanders as statisticians, were integrated. This inclusion of uninvolved bodies and things makes it clear that an affecting took place beyond the habitus and affected not only bodies that came together in the Festival of Life, but also others beyond. On the one hand, the mentioned media discourse and the integration of other bodies and things within the framework of road performance played an enormous role. The involucration of the bodies that appeared to be uninvolved at first glance naturally requires a different kind of definition of protest. During the Yippie! events ironically humorous practices also took place, which attracted attention, distracted the media coverage of Congress and tried to persuade the population that participating in the revolution was more fun than just watching. Yippies in general vetoed the common fact that fun becomes increasingly rarefied as one gets older or like B. Fincham [38] stated: transitioned.

Thus, it is presumed that in addition to the practices of irony and humor, the active involvement of the media was no longer a confrontation, but an elite response that became an integral part of the protest form, and thus the opposition body became active parts of the practice form. Chicago 68 is now mainly remembered as a code word for Police Riot, and only now has protest research in the German-speaking countries begun to include police reactions to protest in their analyses. In most cases, however, police action is still explored in the conventional sense as a context of protest (see Klein [28]). In the opinion of the author, however, this must happen on the foil of the 1968 event within the framework of an analysis strategy that does not draw a distinction. This need emphasized e. g. F. Kusch in his studies about Battleground Chicago very clearly [39]. All the socialised bodies involved must be conceived as elements of the protest. Only then can one look more closely at events without precedent and with sequential character, such as Chicago 1968, and deconstruct it in its constitution, in order to better understand today's protests.

\subsection{Current State of Research Related to Methods of Protest Studies}

Sociology has remained strangely conservative when it comes to the analysis of happenings as a form of protest, and still finds it difficult to classify them, and practice itself, as protest (see Kern [29]). What is being investigated as protest are still mainly demonstrations and organisations around oppositional ideas and goals in social movements. In this case, protesters define targets and use existing resources, which is rather opposed to my research subject. The message of the Yippies! was at most that there is no message. Despite interpretative pattern analyses (see Rucht [30]) and frame analyses [29], research, focussed on the practices of affect and becoming affected, on the disruptive and expressive Yippie! protests has, if anything, been neglected precisely because they did not fit into the definitions of new social movements common in the German-speaking world. Methodically, therefore, surveys (especially) are still carried out, the results of which are then limited to the social-structural classification of the activists and their motives, and political socialisation. Things like affectation and affecting then become marginalised, since, after all, only emotions can be interrogated - which as narratives merely express the perceptible spillover of being affected. But what makes the Chicago event so special is that the interests and goals of the Be-ing were completely unclear and not constitutive of the event. Thus, the Yippies broke the prevailing pattern of justification, mainly because their resistance was not aimed at agreement, as would have been the case for a proper uprising in the sense of L. Boltanski and L. Thevenot [31].

That is why the presented empirical work comprise the practice-theoretical sequence analysis of the documentary movie Chicago 10. Speak Your Peace. a film produced by Laura Bickford et al., written by Brett Morgen [35], with analysis of associations between bodies and artefacts as well as analysis of discourses of the Yippie! discourse. That method enables one to span the relational networks between discourses, recipients, consuments, physical artefacts, socialized bodies and media which one can find between routinized practices of persistence and social change. Initial points are different unprecedented protest events, like the presented example of the Chicago Festival of Life with attachement potential in the revolution of culture related to the social movement in the 1960s. From there one can tell the history of current practices of protest and the emergency of routines and transformation of the formation of practices of protest.

For the first findings presented here a practice-theoretical sequential analysis of the documentary movie was made focused on the interplay between artifacts, bodies and their association by discourses like it is discussed by F. Schäfer / A. Daniel / F. Hillebrandt [36]. Working with such an analytical framework, the challenge is to identify the central elements and dimensions of different practices of affection and to analyze their complex interactions and relations. During the analytical process seven dimensions of practice are differentiated: 1. Dimension of space and time; 2. Dimension of socialized bodies; 3. Dimension of technical and artifacts in general; 4. Dimension of constitutive media elements; 5. Dimension of sound and noise; 6. Dimension of symbols and aesthetics; 7. Dimension of discourses and narratives;

By analyzing the way of association of artifacts, bodies, symbols, discourses, etc. one can see how practices occur and be affective. In doing so, one has to take into account the ceaseless transformation of associations. A simple reproduction of the same combination of elements won't be successful in the long run. Rather, there has to be a 
permanent renewal of the associations between the elements of affective practice, to keep the effect flourishing. The tense relationship of reproduction and renewing these elements and associations evokes the special dynamic of the affective.

\subsection{Preliminary Results}

What, then, is the value of the affective in the context of the specific implementation practice of protests? In the course of the analysis one can now look at what comes together in the Festival of Life that makes socialised bodies affect and be affected. To date, the early state research has come to the initial conclusion that affectivity always occurs when individual elements of a practice form 1. are exaggerated, such as, for example, the physical dimension with the overemphasis of the physical. Affectivity is generated 2. if individual dimensions of practice are interchanged in their meaning, that is, the relations shift, and instead of a socialised human body, e.g. another organic body occupies the same position in the practice chain, which then causes an affecting RemmiDemmi. A wonderful example of this is the nomination and campaigning activities of the American pig Pigasus within the framework of the practices of the Yippie! protests. ${ }^{3}$ In the third place, affectivity arises in the context of protests when conflicting artefacts, with deviating symbolic content, are integrated into practices and transform the social sense or the logic of practice. One could find numerous more examples, but at this point you should pause and ask yourself: For what exactly are we gathering examples, when we're dealing with being and becoming affected? And what should and may a sociology of practice, in particular, look for, and what not?

\subsection{Discussion}

For this purpose the author tried to find orientation from Stähli [4] on alternative forms of analysing affecting protest forms - beyond ideas, goals, and shared values. He first assumes that the affective can produce a kind of restlessness, a goalless movement between bodies. Stähli [4], on the other hand, solves the concept of collectives from the Chicago School tradition, but concentrates equally on the simplest form of the assembly of socialised bodies, which, when one puts things and discourses back into focus, could be entirely in terms of a sociology of the practice of protest. Moreover, Stähli [4] also comes to the conclusion that media discourses play a central role as a connecting element. But first, he diagnoses mobs, flashmobs, panics, and upsets with a common moment of restlessness, which serves what the author is trying to denominate with affect very well. This restlessness is not just an invisible magical feeling, but

3 See more on the Pigasus election campaign online available: http://www.porkopolis.org/2008/pigasus/ (11.04.2017). something that sets something new in motion. So we are looking for something that generates newness and contributes to the dynamics of practice. In this way of thinking, a random gathering of socialised bodies becomes a collective when it becomes dynamic and sets something in motion. Thus Stähli qualifies the exploratory movements of the assembled as forming the constitutive common denominator.

One must, of course, agree to keep in mind that Stähli [4] always speaks clearly of a need for action here, without, however, having to make any reference to an action intention. His idea of affectation as a restlessness that sets bodies in motion, without the movement having a goal, is therefore more than useful. The collective is created by the movement of the body. The restlessness is transferred to the bodies of the others. Through the common acentric movement of bodies and things in association with each other, the individual body or the individual thing becomes the medium of the imitation of movement streams and mediatisation processes are generated. Calculation and meaning comprehension are disturbed by the mediatisation processes and replaced by circular reactions. So much for Stähli [4]. Precisely this constitutes the useful link to affect theory. To the thinking of the Chicago School Stähli [4] adds an additional materiality, which makes it possible to think of spaces and materialities as infrastructures of the collectives, and like Foucault and the practice theories assumes that the practice of the collective must occur. From here, one has to think about how the collective can be conceived beyond the individual event, whereby Foucault and his concept of history of the present can help. In the context of your history of the present of protest, the Yippie! protests become unprecedented events with a sequentials character, which ensure that events occur in series. What Stähli calls the infrastructures of the collective that are necessary for collectives to occur, for they do not do so spontaneously, are in my conception the dimensions of practice that must come together.

Here, however, our common paths separate again, because for Stähli [4] moving assemblies are affective machines. The author of the available paper, on the other hand, is less interested in the $W E$ of the common experience, than in WHAT is gathered and implemented there.

One must not commit the mistake of thinking of the whole as functionalist. Even in the case of Stähli [4], collective structures are not intentionally produced by the human actor, and can often produce precisely that which affects socialized bodies, for example in a football stadium. In some cases, however, other practices also take place that lead to new and completely different forms of practice.

Against the subject-specific, functionalist, or emotional-sociological case-motifs described above, one must therefore, with ontological reflections on the concept of affect, clarify the intentionality: Massumi [1] explains this with great clarity. With him one can be sure, in case of doubt, that affect is not emotion or anything that is felt. An 
affect is the ability of socialised bodies to be affected by other dimensions of practice and to affect them in turn. Affect is thus a physical response to something, and indeed an autonomous response. It is a neutral potential that is physically - as Massumi says, viscerally - generated by a spillover of the conscious stages of perception. For this reason, with Massumi affect is precisely not pre-social, but "open-endedly-social" (Massumi [1] according to Clough [3]). The physical body memory is always social because of the incorporation of the social. Being affected is still visceral, but within this social body. Therefore there is no datum beyond the visible changes of the body surface or body movements - and this is important to emphasise - not even for practice-theoretical exploration. Like James M. Jasper [37] pointed out for culture: the places of cultural meanings are not only our minds, they are as well physical objects and actions. And that is as well the place to look for affectivity in a practice theory approach. Everything else we should leave to Psychologists, we of course should dialog with.

What you can also learn from Massumi is that not only socialised bodies generate affects mutually, but that materiality is also affective. Materiality is communicative, self-organising and, in relation to other dimensions of practice, provides autonomous response to the body. His connections to K. Barad's [32] New Materialism seem worthwhile here.

Affectivity, applied practice-theoretically, is no less but also no more than a movement of physical states between bodies. An affect is the ability to affect and be affected by all kinds of bodies. And for this, bodies and things in relation to one another, discourses, and temporality in spaces are necessary.

\section{Conclusions}

Against the backdrop of these statements, one can say that with a research design such as the one used for this research one needn't with the subject in focus throw the affect as such overboard as well, but could rather - and here on has to agree with Patricia T. Clough [3] - implement the affective turn in such a way that it refers to the discontinuity of the subject and conceives physicalness and materiality in general as constituting moments of sociality [3].

The empirical results in the context of protests show than other than studies about the affective experiences of intentional acting persons, that affectivity occurs when single elements of a practice form are exaggerated, if individual dimensions of practice are interchanged in their meaning or when conflicting artefacts, with deviating symbolic content, are integrated into practices and transform the social sense or the logic of practice.

Not for no reason does Clough [3] refer to the author duo Deleuze and Guattari [31], abundantly quoted by recent practice theories, who define affect as "pre-individual bodily forces augmenting or diminishing a bodys capacity to act" [31, 3] and are deliberately critical of the technologies that make it possible to grasp and manipulate the imperceptible dynamism of affect, as Clough clearly points out.

Limitations of the field of research are that the full potential of bringing discourse, event and practice into a fruitful relationship has not been tapped yet. Also under-explored is the potential for empirical research of documentary dramas like Chicago 10 for analyzing the relationship of discourse and practice in the genealogical history of the present. Other than in existing researches mentioned at the beginning [5-11] one can use the presented research programme to show the communicational double-function of historic materials and present media, building current understandings of protest events as well. My contention is that within a discourse-oriented sociology of practice, as empirical data next to others in line of an advanced multi-sited ethnography through time and space the documentary can tell us something about what protest happened in history and what that tells us about the history of present protests.

The final question, which has emerged from the discussion of the affective, and which one now needs to continue to work on in future research, is the following: Are practices that affect, rather, such practices that are concatenated into practice forms and reconstruct themselves as practice in formation over a longer period of time? This question can only be clarified with an empirical concept of affectedness, as Grossberg also did with ,passion, emotion and affect for politics "[2], in order to be able to collect insofar as bodies are involved in practice - evidence for the measure of affectedness that releases potential for implementation. And only this involvement of bodies starts to be a practice-sociological datum for affects.

The essence of the authors theoretical reflections is, finally, the suggestion that affectedness is a practice which, in its eventuality as a historically contingent intensity zone, like G. Deleuze and F. Guatari [31] highlighted, is constituted with potential for transformation and can only be empirically grasped.

\section{Acknowledgements}

I would like to thank Alexander Antony, Michael Hubrich and Basil Wiesse for giving me the impulse to think about the subject, Frank Hillebrandt for his continuing support and professional influence and the Open University in Hagen for the financial support in terms of the postdoctoral lecture qualification grant. 


\section{REFERENCES}

[1] B. Massumi. Ontomacht. Kunst Affekt und das Ereignis des Politischen, Merve, Berlin, 2010.

[2] L. Grossberg. Affect's Future: Rediscovering the Virutal in the Actual, in: M. Gregg, G. J. Seigworth. The Affect Theory Reader. Merve, Berlin, 309-338, 2010.

[3] P. T. Clough. The Affective Turn. Political Economy, Biomedia, and Bodies, in: M. Gregg, G. J. Seigworth. The Affect Theory Reader. Merve, Berlin, 206-225. 2010.

[4] U. Stäheli. Infrastrukturen des Kollektiven: alte Medien neue Kollektive, Zeitschrift für Medien- und Kulturforschung, Vol 3. No 2, 99-116, 2012

[5] B. Bütow, R. Kahl, A. Stach. Körper, Geschlecht, Affekt. Selbstinszenierungen und Bildungsprozesse in jugendlichen Sozialräumen, Springer, Wiesbaden, 2013.

[6] E. Gutiérrez Rodriguez. Reading affect. On the heterotopian spaces of care and domestic work in private households, Historical Social Research, Vol 33, No 1, 252-277, 2008.

[7] E. Endert. Über die emotionale Dimension sozialer Prozesse. Die Theorie der Affektlogik am Beispiel der Rechtsextremismus- und Nationalsozialismusforschung, UVK, Konstanz, 2006.

[8] J. Butler, J. Mohrmann (Ed.). Krieg und Affekt, Diaphanes, Zürich, 2009.

[9] P. Diehl. Über Emotion, Affekt und Affizierung in der Politik, in: F. Heidenreich, G. S. Schaal (Ed.). Politische Theorie und Emotionen, Nomos, Baden-Baden, 155-176, 2012.

[10] R. Seyfert. Das Leben der Institutionen. Zu einer allgemeinen Theorie der Institutionalisierung, Velbrück Wiss., Weilerswist, 2011.

[11] S. Karakayali. Solidarität und Affekt, in: J. Fischer, S. Moebius (Ed.). Kultursoziologie im 21. Jahrhundert, Springer VS, Wiesbaden, 57-64, 2014.

[12] A. Antony, M. Hubrich and B. Wiesse, Affiziert sein Produktionsweisen der Außeralltäglichkeit, 38th congress of the German Society for Sociology, 93, 2016.

[13] M. Gregg, G. J. Seigworth. The Affect Theory Reader, Merve, Berlin, 2010

[14] B. Latour. Reassembling the Social. An Introduction to Actor-Network-Theory. Oxford University Press, Oxford, 2005.

[15] R. Braidotti, T. Laugstien: Posthumanismus. Leben jenseits des Menschen, Campus, Frankfurt am Main, 2014.

[16] I. Van der Tuin, R. Dolphijn. New Materialism: Interviews \& Cartographies, Open Humanities Press, London, 2012.

[17] F. Hillebrandt. Was ist der Gegenstand einer Soziologie der Praxis?, in: F. Schäfer et al. (Ed.). Methoden einer Soziologie der Praxis, Transcript, Bielefeld, 15-36. 2015.

[18] F. Hillebrandt. Die Soziologie der Praxis als poststrukturalistischer Materialismus, in: H. Schäfer (Ed.). Praxistheorie. Ein Forschungsprogramm, Transcript, Bielefeld, 71-94, 2016.

[19] H. Dietz. Polnischer Protest. Zur pragmatistischen Fundierung von Theorien sozialen Wandels, Campus, Frankfurt am Main, 2015.
[20] D. L. Stein. Living the revolution: the yippies in Chicago. The Bobba-Merill Company, Indianapolis, New York, 1969.

[21] N. Feigelson. The Underground Revolution. Hippies, Yippies, and Others, Funk Wagnalls, New York, 1970.

[22] M. Foucault. Archäologie des Wissens, in: M. Foucault. Die Hauptwerke, Suhrkamp, Frankfurt am Main, 2008.

[23] Federal Statistical Office. Datenreport 2016: Sozialbericht für Deutschland, Kapitel 13: Demokratie und politische Partizipation.

2016: Online available from https://www.destatis.de/DE/Publ ikationen/Datenreport/Downloads/Datenreport2016Kap13.pd $\mathrm{f}$ ? blob=publicationFile (05.01.2017).

[24] A. Reckwitz. Toward a Theory of Social Practices: A Development in Culturalist Theorizing, European Journal of Social Theory, Vol 5, No 2, 243-263. 2002.

[25] T. Schatzki. Social Practices. A Wittgensteinian Approach to Human Activity and the Social, University Press, Cambridge (Ma), 1996

[26] F. Hillebrandt. Soziologische Praxistheorien. Eine Einführung, VS, Wiesbaden, 2014.

[27] B. Latour. Der Berliner Schlüssel. Erkundungen eines Liebhabers der Wissenschaft, Akademie Verlag, Berlin, 1996.

[28] N. Klein, H. Schlatterer. Über Zäune und Mauern. Berichte von der Globalisierungsfront, Campus, Frankfurt am Main, 2003.

[29] T. Kern. Soziale Bewegungen. Ursachen, Wirkungen, Mechanismen. VS, Wiesbaden, 2008.

[30] D. Rucht. Protest in der Bundesregierung. Strukturen und Entwicklungen, Campus Frankfurt am Main, 2001.

[31] L. Boltanski, L. Thévenot. Über die Rechtfertigung. Eine Soziologie der kritischen Urteilskraft, Hamburger Ed, Hamburg, 2007.

[32] K. Barad. Agential Realism. Feminist Interventions in Understanding Scientific Practices, in M. Biagioli. The Science Studies Reader, Routledge, New York - London, 1998.

[33] G. Deleuze, F. Guattari. Tausend Plateaus. Kapitalismus und Schizophrenie, Merve, Berlin, 1993.

[34] M. Foucault. Dits et Ecrits. Schriften in vier Bänden, III. Suhrkamp: Frankfurt am Main, 2003.

[35] B. Morgan. Chicago 10. Speak Your Peace. Film produced by Laura Bickford et al., written by Brett Morgen, Music by Jeff Danna, Edited by Stuart Levy, Production company: Consolidated Documentaries, Participant Productions: River Road Entertainment, Curious Pictures, Distributed by Roadside Attractions, release date: January 18, 2007 (Sundance), 110 minutes, United States, Language: English.

[36] F. Schäfer / A. Daniel / F. Hillebrandt. Methoden einer Soziologie der Praxis. Transcript, Bielefeld, 2015.

[37] J. M. Jasper. The doors that culture opened: Parallels between social movement studies and social psychology. Group Processes \& Intergroup Relations, Vol. 20, No. 3, 285-302, 2017.

[38] B. Fincham. The Sociology of Fun. Macmillan, London, 2016.

[39] F. Kusch. Battleground Chicago: The Police and the 1968 Democratic National Convention, Praeger, Westport, 2004. 